Jurnal Konstruksi Hukum | ISSN: XXXX | E-ISSN: XXXX Vol. 1, No. 2, Oktober 2020, Hal. 369-373| Available online at https://www.ejournal.warmadewa.ac.id/index.php/jukonhum DOI: https://doi.org/10.22225/jkh.1.2.2547.369-373

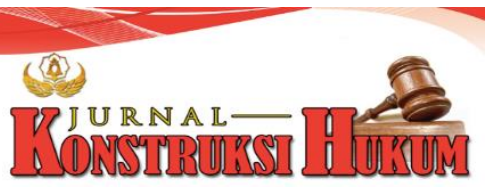

\title{
PENETAPAN HONORARIUM NOTARIS DALAM PRAKTIK PELAKSANAAN JABATAN NOTARIS
}

\author{
I Ketut Adi Gunawan, I Nyoman Sumardika, Ida Ayu Putu Widiati \\ Fakultas Hukum Universitas Warmadewa, Denpasar-Bali, Indonesia
}

\begin{abstract}
Abstrak
Dalam Undang-Undang Jabatan Notaris (UUJN) telah tercantum tentang honorarium, namun dalam praktiknya memiliki batas tertentu. Ketidakpastian dari honorarium bisa menyebabkan kesalahpahaman antara notaris dan klien. Penelitian ini dilakukan dengan tujuan mengungkap apakah penetapan nilai ekonomis dari setiap akta dalam praktik pelaksanaan jabatan notaris sudah sesuai ketentuan UUJN dan apakah seorang notaris bisa memberikan jasa hukum di bidang konotariatan kepada orang yang kurang mampu. Penelitian ini didesain dengan menggunakan metode penelitian yuridis-empiris. Hasil penelitian ini menunjukkan bahwa penetapan nilai ekonomis dari setiap akta dalam praktik pelaksanaan jabatan notaris sudah sesuai dengan ketentuan UUJN yang diatur dalam pasal 36. Semua pejabat umum yang sudah menyetujui tentang pengaturan honorarium menyatakan supaya harus memiliki rasa mengikat dan adanya kekuatan paksaan yang disesuaikan dengan ketentuan di UUJN. Selain itu, seorang notaris bisa memberikan jasa hukum di bidang konotariatan kepada orang yang kurang mampu dengan didasari oleh moralitas dan intergritasi seorang notaris. Hal ini didukung oleh pasal 37 UUJN yang menyatakan bahwa notaris wajib memberikan jasa secara cuma-cuma kepada orang yang tidak mampu.
\end{abstract}

Kata Kunci: Honorarium; Notaris; UUJN

\begin{abstract}
The Law on Notary Position (hereafter called UUJN) states the honorarium, but in practice, it has certain limits. The uncertainty of honoraria can lead to misunderstanding between the notary and the client. This research was conducted with the aim of revealing whether the determination of the economic value of each deed in the practice of implementing the position of a notary is in accordance with the provisions of the UUJN and whether a notary can provide legal services in connotarial matters to underprivileged people. This research was designed using juridical-empirical research methods. The results of this study indicated that the determination of the economic value of each deed in the practice of implementing the position of a notary is in accordance with the provisions of UUJN as stipulated in article 36. All public officials who have agreed on the arrangement of the honorarium state that they must have a sense of binding and the existence of coercive power which is adjusted to the provisions in UUJN. In addition, a notary can provide legal services in the field of connotarization to underprivileged people based on a notary's morality and integrity. This is supported by Article 37 of the UUJN which states that notaries are required to provide services free of charge to people who cannot afford it.
\end{abstract}

Keywords: Honorarium; Notary; UUJN

\section{PENDAHULUAN}

Notaris ialah pejabat yang umum yaitu sebuah profesi, posisi sangat mementingkan untuk membantu dalam memberikan kepastian hukum dikalangan masyarakat. Mencegah terjadinya permasalahan hukum di kemudian hari melalui akta otentik yang dibuatya sebagi alat pembuktian yang sempurna di pengadilan. Notaris merupakan profesi yang terhormat selalu lekat dengan etika dan dengan etikalah Notaris berhubungan dengan pekerjaan. Tanpa etika, Notaris hanyalah robot-robot mekanis yang bergerak dalam tanpa jiwa. Karena lekatnya etika pada profesi Notaris disebut sebagai profesi mulia (officium nobile) (Abdul Ghofur Anshori, 2009).

Posisi notaris harus independen atau netral artinya notaris diharapkan untuk memberikan penyuluhan hukum untuk dan atas tindakan hukum yang dilakukan notaris atas permintaan kliennya. Dalan hal melakukan tindakan hukum untuk kliennya, notaris juga tidak boleh memihak kliennya, karena tugas notaris ialah untuk mencegah terjadinya masalah (Supriyanta, 2013). Jika memang notaris 
ingin menolak untuk memberikan jasanya kepada pihak yang membutuhkannya, maka penolakan tersebut harus merupakan penolakan dalam arti hukum, dalam artian ada alasan atau argumentasi hukum yang jelas dan tegas sehingga pihak yang bersangkutan dapat memahaminya (Bagus, 2018).

Selain kewajiban untuk melakukan hal-hal yang telah diatur dalam UU, notaris masih memiliki kewajiban lain. Jadi ini berhubungann dengan sumpah/janji notaris yang berisi bahwa seorang pejabat umum akan merahasiakan isi akta dan keterangan yang diperoleh dalam melaksananakan jabataannya kecuali jika diperiintahkan oleh UU bahwa notaris tidak wajib merahasiakan dan memberikan keterangan yang diperlukan yang bersangkutan dengan akta tersebut (Putri \& Prananingtyas, 2019). Dengan demikian, hanya UU saja yang dapat memerintahkan notaris untk membuka isi rasia akta dan keterangan atau pernyataan yang diketahui oleh notaris yang berkaitan dengan pembuatan akta.

Penetapan besarnya honorarium Notaris didasarkan pada nilai ekonomis dan nilai sosiologis dari setiap akta yang dibuatnya, sebagaimana yang diatur dalam pasal 36 Undang-Undang Nomor 30 Tahun 2004 tetang Jabatan Notaris. Selain didasarkan atas ketentuan pasal 36 UUJN besarnya honorarium juga berdasarkan atas penetapan perkumpulan (Ikatan Notaris indonesia), sebagaimana dalam Kode Etik Notaris pada pasal 3 angka (13) Kode Etik, notaris diwajibkan melaksanakan dan mematuhi ketentuan tentang honorarium yang ditetapkan perkumpulan. Sedangkan bedanya terhadap masyarakat yang kurang mampu yang belum dapat memberikan honorarium karena ekonomi yang berdapak kepada notaris. Notaris pada dasarnya belum bisa menolak orang yang tidak mampu yang datang untuk meminta jasanya, dalam ketentuan UUJN di bidang kenotariatan terhadap orang yang kurang mampu atau belum mampu (Ningsih dkk., 2019).

Ada beberapa penelitian terdahulu yang relevan dengan penelitian ini yaitu penelitian yang mengungkapkan Notaris yang melanggar Peraturan Dewan Kehormatan Pusat Nomor 1 Tahun 2017 dapat dikenakan sanksi internal dan sanksi eksternal (Kartikosari \& Sesung, 2017). Penelitian lain mengungkap bahwa Pengaturan tentang honorarium Notaris yang diatur dalam UUJN dan Kode Etik Notaris (SukoPrayitno \& Hutabarat, 2019). Penelitian lain mengungkapkan bahwa Penetapan tarif Notaris yang diatur dalam Undang-undang Jabatan Notaris hanya seputar pembuatan akta dan mengatur batas maksimum honorarium saja, selanjutnya Perjanjian penetapan besaran minimal honorarium dan untuk jasa pelengkap akta seorang Notaris berpedoman pada Kode Etik Notaris, kemudian pengurus masing-masing daerah Ikatan Notaris Indonesia akan mengadakan kesepakatan antara semua anggota agar didapatkan hasil yang sesuai kesepakatan bersama (Yuniati \& Wahyuningsih, 2017). Penelitian ini dilakukan dengan tujuan mengungkap apakah penetapan nilai ekonomis dari setiap akta dalam praktik pelaksanaan jabatan notaris sudah sesuai ketentuan UUJN dan apakah seorang notaris bisa memberikan jasa hukum di bidang konotariatan kepada orang yang kurang mampu.

\section{METODE PENELITIAN}

Penelitian ini didesain dengan menggunakan penelitian yuridis-empiris yaitu jenis penelitian hukum sosiologis yang dapat juga disebut dengan peneitian lapangan, yaitu mengkaji hukum yang berlaku serta apa yang terjadi dalam kenyataan masyarakat (Bambang, 2002). Pendekatan yang digunakan adalah pendekatan perundang-undangan dengan cara menelaah regulasi dan undang-undang yang berkaitan dengan fokus penelitiam. Sumber data yang digunakan adalah sumber hukum primer dan sekunder dengan teknik analisis data secara kualitatif.

\section{HASIL DAN PEMBAHASAN}

\section{Penetapan Nilai Ekonomis Pelaksanaan Jabatan Notaris Sesuai Ketentuan UUJN}

Terdapat dua asas yang mempengaruhi sistem imbalan jasa. Pertama, asas melayani sebatas upah yang diterima. Kedua, asas melayani sesuai permintaan (Surmayono, 2003). Jabatan Notaris memungkinkan untuk melayani permintaan para penghadap mengenai pekerjaan selain pembuatan akta autentik dengan menerima honorarium yang disepakati. Inilah yang menjadi kebutuhan bahwa Notaris dalam menjalankan jabatannya tidak hanya sekedar mengandalkan mendapatkan honorarium sesuai UUJN, tetapi ada juga honorarium yang didapatkan dari masyarakat atas jasa hukum yang diluar dari kewenangannya seperti diatur dalam UUJN.

Penetapan honorarium yang lebih kecil dari ketentuan notaris atas jasa pembuat akta otentik penetapan biayajasa tersebut dengan berbagai cara (Yunita Laytno \& Setiabudhi, 2019). Perjanjian tersebut menentukan pekeraan notaris tersebut, berapa jangka watku pembuat akta, beberapa honor 
yang diterima oleh notaris dalam akta yang dibuatnya. Pengaturan honorarium notaris dalam hal pembuat akta otentik dalam Pasal 36 UUJN menentukan bahwa:

a. Notaris berhak menerima honorarium atas jasa hukum yang diberikan sesuai dengan kewenangannya.

b. Besarnya honorarium yang diterima oleh Notaris didasarkan pada nilai ekonomis dan nilai sosiologis dari setiap akta yang dibuatnya.

c. Nilai ekonomis sebagaimana dimaksud pada ayat (2)ditentukan dari objek setiap akta

d. Sampai dengan Rp100.000.000,00 seratus juta rupiah atau ekuivalen gram emas ketika itu, honorarium diterima paling besar adalah $2,5 \%$

e. Di atas dengan Rp 100.000.000,00 seratus juta rupiah sampai dengan Rp 1.000.000.000,00 satu miliar honorarium yang diterima paling besar $1,5 \%$

f. Di atas Rpl.000.000.000,00 satu miliar rupiah honorarium yang diterima didasarkan pada kesepakatan antara Notaris dengan para pihak, tetapi tidak melebihi $1 \%$ sesuai dengan objek yang dibuatkan aktanya

g. Nilai sosiologi ditentukan berdasarkan fungsi social dari objek setiap akta dengan honorarium yang diterima paling besar Rp5.000.000,00 lima juta rupiah.

Dalam Pasal 36 Ayat (2) UUJN berbunyi, "Besarnya honorarium yang diterima oleh notaris didasarkan pada nilai ekonomis dan sosiologis dari setiap akta yang dibuatnya. Dari beberapa persen nilai sosiologis dan ekonomis perlu ditetapkan" Hal ini sangatlah sulit dikarenakan notaris menentukan nilai pasti sosologis terhadap dibuatkannya akta tersebut. Kenyataanya UUJN pasal 36 ayat 2 kurang memuaskan, bisa dikatakan besar honorarium yng dibuat oleh pejabat umum berdasarkan nilai pasti ekonomis dan nilai pasti sosiologis dari semua akta yang dibuat, berarti untuk semua akta harus dicari 2 nilai pasti yakni nilai pasti ekonomis dan nilai pasti sosiologi, dengan inipasti akan menyulitkan pejabat umum untuk mengetahui pasti beberapa nilai ekonomi dan juga nilai pasti sosiologi untuk mencari kepastian hasil akhinya. Honorarium yang akan diterima oleh pembuat akta tersebut didasarkan oleh besarnya pasti hasil ekonomi dan hasil dri sosiologi dengan yang dibuatkanny akta tersebut. Selanjutnya didalam penjelasan tentang pasal 36 ayat 4 bahwa akta yang mempunyai kepatian didalam sosiologi dan memiliki tugas social berdasarkan pasal 36 UUJN. Contohnya akta pendirian yayasan, akta pendirian sekolah dan akta pembangunan rumah sakit. Selain itu pasal 37 UUJN menyebutkan bahwa notaris wajib memberikan jasa secara cuma-cuma kepada orang yang tidak mampu.

Dengan persaingan kurang bagus ini antar semua pejabat umum, kode etik harus ada dengan tujuan agar supaya tidak adanya saingan kurang enak terhadap pejabat umum. Sama seperti UUJN, kodeetik notaris ini belum memberikan pemberitahuan yang sudah cukup sangat jelaas tentang saingan ini dengan demikian dapat diuraikan ke pasal 4 ayat 9 kode etik yang memberitahu yaitu : "notaris yang mengaku menjalankan jabatan notaris dilarang melakukan usaha usaha, baik langsung maupun tidak langsung yang menjadi saingan kurang baik semama notaris (Ningsih et al., 2019).

Honorarium diatur dalam orgnisasi jabatan notaris dengan ditetapkan tarif minimum jasa notaris supaya tercapai kesetaraan setiap notaris. Kemudian diberikan hukuman berupa saknsi pelanggaran terhadap jasa notaris tersebut. Berdasarkan hasil wawancara dengan responden notaris I Made Kembar Bagiasa, S.H. dengan ini pengurangan biaya notaris yang diberikan bila seorang kurang mampu melunasi akta yang dia buat, dengan itu notaris memastikan seberapa sanggupnya seorang tersebut dapat membayar.

\section{Pemberian Jasa Hukum di Bidang Konotariatan Kepada Orang yang Kurang Mampu}

Kewajibannya UUJN menyangkut pemberian jasa hukum kepada orang yang kurang mampu, ada tiga penyebab yaitu: kemanusiaan, keterusterangan klien yang bertemu kehadapannya, kepastian notaris kepada klien yang menghadap bahwa orang tersebut kurang mampu. Dari hasil di lapangan dengan pihak yang memakai jasa hukum dibidang kenotariatan dengan memakai bahwa ada beberapa faktor yang membelakangi notaris memberikan jasa kepada orang yang tidak mampu yaitu adanya rasa kemasyarakatan yang memiliki jiwa sosial dan persaudaraan.

Menurut responden narasumber, pembagian honoraium notaris tidak semuanya diambil melainkan untuk kepentingan kantor juga seperti gaji pegawai selaku tenaga kerja, daya listrik sebagai penyaluran untuk komputer dan alat-alat yang lainnya. Seorang notaris lebih mementingkan pelayanan kepada masyarakat ketimbang pendapatan, yang diartikan mementingkan yang harus dilakukan dan tidak 
memikirkan besar atau kecil pendapatan yang diterima oleh klien karenakepentingannya. Dengan ini pendapatan sendirinya dipenuhi sendiri dengan wajar apabila klien puas dengan pelayanan yang diberikan. Setiap klien yang datang kekantor notaris baik orang yang mampu ataupun orang yang kurang mampu memiliki kewajiban yang rata supaya bisa memakai jas hukum dibidang kentariatan. Berdasarkan uraian tersebut, penghadap sudah memenuhi dasar udang udang serta persiapan yang harus dilakukan dalam jas hukumnya dibidang kenotariatan yang sudah terpenuhi, jadi sudh tidak lagi adanya hambatan oleh notaris khususnya dalam memberikan jasa kenotariatannya.

Hukum didalam dunia kenotariaan haruslah mengacu dalam UUJN dan patuh terhapda kode etik noatris, supaya dalam menjalani sebuah profesi ini notaris diharuslah baik dilingkungan masyarakat agar tidak dipandang semena mena dan harus mempunyai harkat martabat yang kuat suapa tidak terjadinya keluhan yang terjadi (Prasetiyo, 2017).

Maka seorang Notaris tidak bisa menolak permintaan seorang klien untuk membuat suatu akta otentik karna sudah menjadi tugas pejabat pembuat akta. Bila mana seorang pejabatn umum yang tidak mau membuatkan akta tanpa adanya aturan yang kurang jelas tersebut, maka diberikan berupa sanksi yang sudah diatur oleh undang-undang.

Kendala penerapan Pasal 37 Ayat (2) UUJN yaitu:

a. Ketidak tahuan masyarakat prosedur pelaporan.

b. Pengawasan MPD, MPW, MPP.

c. Adanya batasan pemberian jasa hukum kepada orang yang tidak mampu.

Kepastian yang di berikan dibagi menjadi dua bagian yaitu: Pengaturan yang sifatnya umum serta individu yang membuat perbutan yang tidak boleh tersebut serta yang kedua Penjagaan hukum bagi semua individu bagi kesewenangan perintah karena ada peraturan bersifat umum sendiri yang dibebankan oleh negara terhadap individu.

\section{SIMPULAN DAN SARAN \\ Simpulan}

Berdasarkan hasil analisis data dapat disimpulkan bahwa penetapan nilai ekonomis dari objek setiap akta dalam praktik pelaksanaan jabatan notaris sudah sesuai dengan ketentuan UUJN. Semua pejabat umum yang suda menyetujui tentang pengaturan honorarium menyatakan supaya harus memiliki rasa mengikat dan adanya kekuatan paksaan yang disesuaikan dengan ketentuan UUJN. Dengan ini notaris akan memberikan jasa hukum kepada orang yang kurang mampu dengan didasari oleh moralitas dan intergritasi seorang notaris karena ilmu dan wawasan yang kurng atau berkecukupan mengenai kegunaan dengan mengunakan kewajibannya ini tidak bisa diterapkannya diprofesi lingkungan yang sangat luas yaitu masyarakat.

\section{Saran}

Mengingat asas daripada hukum adalah keadilan, kepastian hukum dan manfaat hukum maka penulis menyarankan perlu diadakan perubahan pasal 36 UUJN juga menyebutkan batas minumum honorarium yang ditetapkan organisasi notaris. Seorang notaris sebaiknya tidak boleh mempersulit seseorang yang sedang membutuhkan layanan hukum di bidang kenotariatan dengan masyarakat kurang mampu dan masyarakat yang mampu. Semua masyarakat yang datang ke kantor notaris memiliki kewajiban berupa melayani jas hukum dibidang kenotariatan yang sudah ada dalam ketentuan di UUJN

\section{DAFTAR PUSTAKA}

Bagus, I. (2018). Prinsip Kehati-Hatian Notaris dalam Membuat Akta

Bambang, W. (2002). Penelitian Hukum dalam Praktek. Sinar Grafika.

Kartikosari, H., \& Sesung, R. (2017). Pembatasan Jumlah Pembuatan Akta Notaris oleh Dewan Kehormatan Pusat Ikatan Notaris Indonesia. Jurnal Panorama Hukum, 2(2), 167-184.

Ningsih, A., Faisal, \& Adwani. (2019). Kedudukan Notaris sebagai Mediator Sengketa Kenotariatan Terkait dengan Kewajiban Penyuluhan Hukum. Mimbar Hukum, 27(1), 15-28.

Prasetiyo, A. (2017). Kewajiban Notaris dalam Menjalankan Prinsip Tata Kelola Kantor Notaris. Jurnal Akta, 4(3), 441-448.

Putri, N., \& Prananingtyas, P. (2019). Peran Ikatan Notaris Indonesia (INI) dalam Penetapan Tarif di Antara Notaris Kota Balikpapan. Journal of Chemical Information and Modeling, 12(1), 134-146.

SukoPrayitno, I., \& Hutabarat, E. A. (2019). Akibat Hukum terhadap Pelanggaran atas Ketentuan Honorarium Akta Notaris. Res Judicata, 2(1), 186-199. 
Supriyanta. (2013). Kajian Filosofis terhadap Standar Perilaku Etis Notaris. Yustisia Jurnal Hukum, 2(3), 137144.

Surmayono, E. (2003). Etika Profesi Hukum. Kanisius.

Yuniati, S., \& Wahyuningsih, S. E. (2017). Mekanisme Pemberian Sanksi terhadap Notaris yang Melakukan Pelanggaran kode Etik Jabatan Notaris. Universitas Nusantara PGRI Kediri, 4(4), 585.

Yunita Laytno, V., \& Setiabudhi, I. K. R. (2019). Sinkronisasi Pengaturan Honorarium Jasa Notaris antara UUJN dengan Kode Etik Notaris. Acta Comitas, 4(1), 22-33. 